Available online at GSC Online Press Directory

GSC Biological and Pharmaceutical Sciences

e-ISSN: 2581-3250, CODEN (USA): GBPSC2

Journal homepage: https://www.gsconlinepress.com/journals/gscbps

(RESEARCH ARTICLE)

\title{
Levels of pro-inflammatory biomarkers among HIV patients on highly active antiretroviral therapy (HAART) and HAART naive patients
}

\author{
Wiredu Osei Kwame 1* ${ }^{*}$, Edzeamey Fred Jonathan ${ }^{2}$, Frempong Margaret Twimasiwah ${ }^{1}$, Gborgblorvor \\ Delphine ${ }^{3}$, Sampong Bernard Berko ${ }^{2}$, Awuah Maxwell ${ }^{4}$ and Dompreh Albert ${ }^{5}$ \\ ${ }^{1}$ Department of Molecular Medicine, School of Medical Sciences, Kwame Nkrumah University of Science and Technology, \\ Ghana. \\ ${ }^{2}$ Laboratory Department, Ashanti-Bekwai Municipal Hospital, Ghana. \\ 3 Department of Out-Patients', Ashanti-Bekwai Municipal Hospital, Ghana. \\ ${ }^{4}$ Department of Medical Laboratory Technology, School of Allied Health Sciences, University of Cape Coast, Ghana. \\ 5 Serology Department, Komfo Anokye Teaching Hospital, Kumasi, Ghana.
}

Publication history: Received on 26 June 2018; revised on 08 July 2018; accepted on 13 July 2018

Article DOI: https://doi.org/10.30574/gscbps.2018.4.2.0056

\begin{abstract}
Inflammation is the immune response of the body to infection and injury. Inflammation aims at eliminating the pathogen or causative agent, removing necrotic cells and tissues and initiating repair process. IL-6. TNF- $\alpha$ and CRP are biomarkers of inflammation. This study sought to determine the pro-inflammatory markers among HIV patients on HAART and HAART naïve patients. This was a hospital-based, case control study conducted among 150 participants. HIV patients' on HAART $(n=50)$ and HAART naïve HIV $(n=50)$ patients and the control group $(n=50)$ was HIV Seronegative individuals. Venous blood was drawn from each of the participant. Serial dilutions of standards of TNF- $\alpha$, IL- 6 and CRP were made and mixed with $10 \mu \mathrm{L}$ of patients' blood. Absorbance was read at 450nm within 15 min with Mindray MR96A reader. Among the study population, IL-6 levels was higher in HAART naïve HIV patients 17.66(13.00 - 24.10) ng/L, and these same group also recorded the highest CRP and TNF- $\alpha$ levels of 1453(328.8 - 2510) $\mu \mathrm{g} / \mathrm{L}$ and 318.3(123.0 497.9) ng/L respectively. The present study revealed elevated levels of pro-inflammatory cytokines (IL-6, CRP and TNF$\alpha$ ) in seropositive HIV groups compared to seronegative group.
\end{abstract}

Keywords: Pro-inflammatory; HAART naïve; HIV; Biomarkers

\section{Introduction}

Inflammation is the immune response of the body to infection and injury. Inflammation aims at eliminating the pathogen or causative agent, removing necrotic cells and tissues and initiating repair process. Inflammatory markers such as IL6 , TNF- $\alpha$ and C - reactive protein (CRP) play some vital roles in the pathogenesis of HIV. Tumour necrosis factor (TNF) a glycoprotein of 185-amino acid was isolated in 1975. It is connected to the cell surface of mononuclear phagocytes by 212 amino-acid peptide. Macrophages are the main source of TNF although T cells, NK cells and mast cells when activated may secrete TNF. Interferon also supplements TNF synthesis. TNF attracts more inflammatory cells to the site of infection and elevated levels causes' heat, swelling, redness and pain at the site of infection. It also exerts systemic protective effect on the hypothalamus region of brain which causes fever. High levels TNF- $\alpha$ is understood to speed up pathogenesis in HIV patient [1] by supporting the NF- $\kappa$ B pathway transcription of new virion [1-3]. In human IL-6 is encoded as IL-6 gene and acts as pro-inflammatory and anti-inflammatory myokine. Macrophage, T cell, fibroblast and vascular endothelial cells release IL- 6 when the body experience inflammation, burns and tissue damage. Just as TNF

\footnotetext{
${ }^{*}$ Corresponding author

E-mail address:wiredseio@yahoo.com
}

Copyright (C) 2018 Author(s) retain the copyright of this article. This article is published under the terms of the Creative Commons Attribution Liscense 4.0. 
and IL-1, IL-6 also causes fever. IL-6 aids in the attraction of neutrophils to the site of infection and also initiate differentiation of B cells. IL- 6 also stimulates the hypothalamus to synthesize Prostaglandin $\mathrm{E}_{2}$ which ensures changes in the set point of the body temperature. IL- 6 is noted to be high in retroviral infection, autoimmune diseases and benign or malignant tumor patients and promotes HIV [4-6]. It mediates T-cell activation, stimulates proliferation of keratinocytes and at the beginning of acute inflammation, mediates the acute phase responses[7, 8].There is increasing evidence that Il-6 is an important factor in pathogenesis of atherosclerotic disease and associated abnormalities of the serum lipid $[9,10]$. In monocytic cells, IL-6 co-operates with TNF- $\alpha$ to augment HIV-1 replication at transcriptional and posttranscriptional levels [11]. During Acute phase response of chronic inflammation caused by bacteria, virus and other pathogens, there is an increase secretion of Il-6 from macrophage and adipocytes [12]. The rise in Il-6 level triggers the liver [13] to secret C-reactive protein (CRP). CRP is a ring-shaped, pentameric protein synthesize by activated hepatocytes in response to acute inflammation. CRP ensures phagocytosis by macrophage through it attachment to the phosphocholine on the surface of the antigen and then links it to the macrophage CRP receptor to complete opsonin-mediated phagocytosis. It may increase 50,000 times its initial level within two hour during inflammation and sustains for 48 hours. At a serum concentration of $10 \mathrm{mg} / \mathrm{L}$ in healthy human, it can increase as high as $40 \mathrm{mg} / \mathrm{L}$ during viral infection; $40-200 \mathrm{mg} / \mathrm{L}$ in bacterial infection and $>200 \mathrm{mg} / \mathrm{L}$ during severe bacterial infection and burns [7, 14]. CRP can be a good indicator of immune activation in response to inflammatory damage or infection and has been shown to increase in HIV-1 infected individuals [13, 15]. CRP have been related to cardiovascular disease $[14,16]$ and atherosclerotic disease as well as some of the common diseases in PLWHAs. This study therefore sought to determine the levels of inflammatory cytokines in HIV patients on HAART and HAART naïve patients.

\section{Material and methods}

This was a hospital-based, case control study conducted from June to November 2014 in the Komfo Anokye Teaching Hospital (KATH), Kumasi, Ghana. 150 participants in all were recruited for this study. Hundred participants were recruited from the HIV clinic at KATH out of which 50 were on ART and the other 50 participants were treatment naïve. The 50 control group was selected from client visiting the blood bank unit of KATH to make voluntary donation. Whilst HIV patients between 18-45 years, newly diagnosis patient for at most six months for HAART naïve, HIV patient on HAART for at most one year and HIV patients without Immuno-compromised infection (example Tuberculosis, HCV, HBV) were included in the study, Patients with Hemoglobin levels less than 8g/dl and those having any Immunocompromised infection (example Tuberculosis, HCV, HBV) were excluded from the study. Also, the exclusion criteria for the control group were the same as those of the patients aside being negative for HIV.

\subsection{Sample collection}

$7 \mathrm{ml}$ of venous blood was drawn from each of the participant by venepuncture; $3 \mathrm{ml}$ into K3-EDTA Vacutainer tube and $4 \mathrm{ml}$ in coagulated tube. CD4 counts were done on each sample in the anti-coagulated tube. However, the blood samples in the BD Vacutainer ${ }^{\circledR}$ SST ${ }^{\mathrm{TM}}$ Gel Separator Tubes were allowed to clot and serum obtained by centrifuging it at 3000 revolutions per minute (rpm). The serum samples were pipetted into cryogenic storage tubes and accumulated for a month at $-20^{\circ} \mathrm{C}$ prior to immunological analyses.

\subsection{Determination of biomarkers}

In this study, different concentration of the TNF- $\alpha$ standard $(400,200,100,50$ and $25 \mu \mathrm{g} / \mathrm{L}), \mathrm{CRP}$ standard (2400, 1200, $600,300$ and $150 \mu \mathrm{g} / \mathrm{L})$ and IL- 6 standard $(20,10,5,2.5$ and $1.25 \mu \mathrm{g} / \mathrm{L})$ was prepared by serial dilution using standard diluent. The samples were prediluted in a 1:150 ratio with a zero standard. $40 \mu \mathrm{l}$ of the standards (TNF- $\alpha$, IL-6 or CRP) and $10 \mu \mathrm{l}$ patient sample was pipetted into the respective micro titre wells. The plate was tapped gently to mix the content; the plate was sealed and incubated at $37{ }^{\circ} \mathrm{C}$ for 30 mins. The wells were washed five (5) times with diluted wash buffer (diluted 30 folds with distilled water). After drying, $50 \mu$ l horseradish peroxidase (HRP)-Conjugate reagent was added to each well, except blank well. The plate was then covered and incubated at 37 o $\mathrm{C}$ for 30 minutes. The liquid was discarded after incubation and washed with a buffer solution repeatedly for five times and dried by patting. After that $50 \mu \mathrm{l}$ of tetramethylbenzidine (TMB)-peroxide substrate colour developer was added to each well and incubated for $10 \mathrm{~min}$ at $37^{\circ} \mathrm{C}$. Finally $50 \mu \mathrm{l}$ of stop solution is added to each well to stop the reaction. Absorbance was read at 450 nm within 15 min with Mindray MR-96A reader.

\subsection{Statistical analysis}

The data was analyzed using the Statistical Package for Social Scientist (SPSS) Statistical Software (version 17.0, SPSS Inc., Chicago, IL, USA). Continuous variables which were expressed as mean \pm standard deviation (SD) and nonparametric were express as median with interquartile range. For all statistical comparisons, the level of significance was set at $p<0.05$. 


\section{Results}

\subsection{Demographic characteristics of study population}

The mean age of the HIV patients $(38.57 \pm 1.13$ for those on treatment and $37.25 \pm 1.19$ for treatment naive) were significantly higher $(\mathrm{P}<0.0001)$ respectively than that of the controls $(22.35 \pm 1.03)$. The female participants $(42$ for those on treatment and 36 for the treatment naïve) far outnumber the male participants ( 8 for on-treatment and 14 for treatment naïve). However for the controls the number of males (37) was almost three times the number of females (13) (Table 1).

Table 1 Socio-demographic characteristics of study participants

\begin{tabular}{lllll}
\hline & & \multicolumn{2}{c}{ HIV Patients } \\
& Control (n=50) & On HAART (n=50) & HAART Nä̈ve(n=50) & P-value \\
\hline $\begin{array}{l}\text { Age (years) } \\
\text { Gender (\%) }\end{array}$ & $22.35 \pm 1.03$ & $38.57 \pm 1.13^{++\dagger}$ & $37.25 \pm 1.19^{+\dagger+}$ & $<0.0001$ \\
Male & $37(74.0 \%)$ & $8(16.0 \%)$ & & \\
Female & $13(26.0 \%)$ & $42(84.0 \%)$ & $36(72.0 \%)$ & \\
\hline \multicolumn{5}{r}{ Values are presented as mean \pm standard deviation (SD) and frequency (percentage) }
\end{tabular}

Table 2 shows median levels of proinflammatory cytokines in the study population. There was a significantly higher median levels of IL-6, CRP and TNF- $\alpha$ in the order of Control<on-treatment group $<$ treatment naïve group ( $<<0.0001$ ) (Table 2).

Table 2 Level of pro-inflammatory markers in general studied population

\begin{tabular}{|c|c|c|c|c|}
\hline \multirow[b]{2}{*}{ Biomarkers } & \multirow[b]{2}{*}{ Control $(n=50)$} & \multicolumn{2}{|c|}{ HIV Patients } & \multirow[b]{2}{*}{ P-value } \\
\hline & & On HAART $(n=50)$ & HAART Naïve $(n=50)$ & \\
\hline IL-6 (ng/L) & $4.454(1.274-8.725)$ & $14.98(5.875-24.93)^{\dagger+\dagger}$ & $17.66(13.00-24.10)^{\dagger+\dagger}$ & $<0.0001$ \\
\hline $\mathrm{CRP}(\mu \mathrm{g} / \mathrm{L})$ & $156(117.1-582.2)$ & $1450(251.3-2688)^{+\dagger \dagger}$ & $1453(328.8-2510)^{+\dagger \dagger}$ & $<0.0001$ \\
\hline TNF- $\alpha(n g / L)$ & $40.28(24.73-81.00)$ & $297.4(150.2-419.7)^{\dagger+\dagger}$ & 318.3(123.0 - 497.9)††† & $<0.0001$ \\
\hline
\end{tabular}

\subsection{CD4 Count Analysis for study population}

Mean levels of CD4 was significantly lower among treatment and treatment naïve HIV infected participants compared to control $(\mathrm{p}<0.0001)$ (Table 3.0).

Table 3 Depicts the CD4 count among the study population

\begin{tabular}{lllll}
\hline & & \multicolumn{3}{c}{ HIV Patients } \\
& Control $(\mathbf{n = 5 0})$ & On HAART $(\mathbf{n = 5 0})$ & HAART Naïve (n=50) & P-value \\
\hline CD4 (cells/mm) & $1084 \pm 55.40$ & $498.5 \pm 43.85^{\dagger+\dagger}$ & $506.7 \pm 60.58^{++\dagger}$ & $<0.0001$ \\
\hline
\end{tabular}

Values are presented as mean \pm SD. $\uparrow \mathrm{p}<0.05$; $\uparrow \dagger \mathrm{p}<0.001 ; \dagger+\uparrow \mathrm{p}<0.0001$ HIV patients (On-treatment and treatment naïve groups) compared to control

\subsection{Pro-inflammatory cytokines in relation to the severity of CD4 count}

Median levels of pro-inflammatory cytokines (IL-6, CRP and TNF-Alpha) significantly increased with decreasing CD4 count. Subjects with CD4 counts less than 200 cells/mm3 were associated with a significantly higher median levels of IL-6, CRP and TNF-Alpha compared to those with CD4 count of 500 cells $/ \mathrm{mm} 3$ and more $(\mathrm{p}<0.05)$ in all the three groups 
(Figures 1, 2 and 3) respectively. The level of proinflammatory cytokines were further stratified by gender as depicted in Table 4.

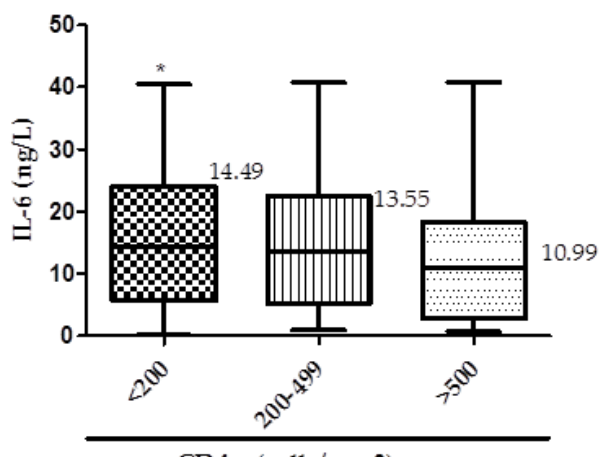

Figure 1 IL- 6 relation to the severity of CD4 count among the studied population ${ }^{*} \mathrm{P}<0.05 ;{ }^{* *} \mathrm{p}<0.001{ }^{* * *} \mathrm{p}<0.0001$. Each CD4 count $<200$ and $200-499$ compared $>500$ cells $/ \mathrm{mm} 3$

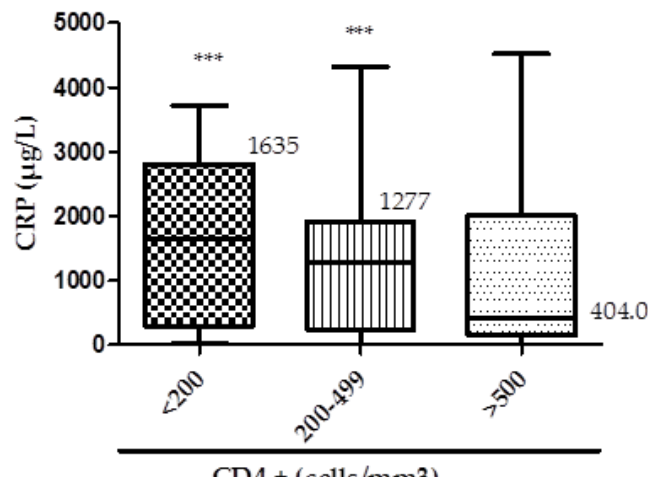

$\mathrm{CD} 4+($ cells $/ \mathrm{mm} 3)$

Figure 2 CRP relation to the severity of CD4 count among the studied population ${ }^{*} \mathrm{P}<0.05 ;{ }^{* *} \mathrm{p}<0.001{ }^{* * *} \mathrm{p}<0.0001$. Each CD4 count $<200$ and $200-499$ compared $>500$ cells $/ \mathrm{mm} 3$.

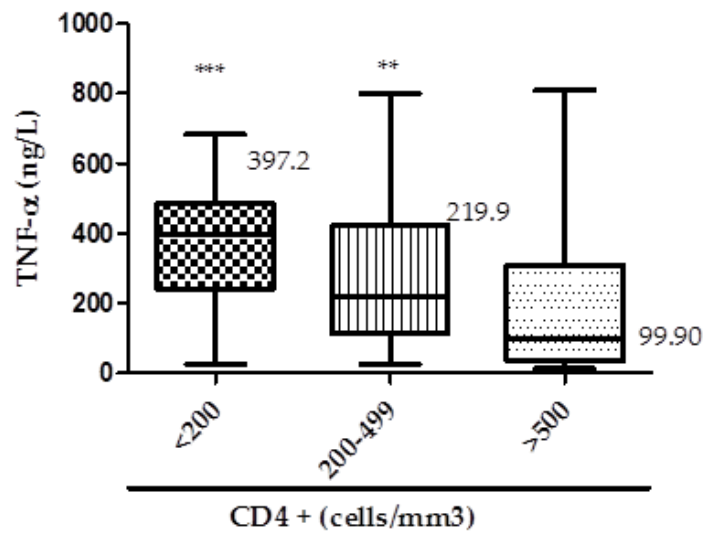

Figure 3 TNF- $\alpha$ relation to the severity of CD4 count among the studied population ${ }^{*} \mathrm{P}<0.05 ;{ }^{* *} \mathrm{p}<0.001{ }^{* * *} \mathrm{p}<0.0001$. Each CD4 count $<200$ and $200-499$ compared $>500$ cells $/ \mathrm{mm} 3$. 
Table 4 Pro-inflammatory cytokines stratified by gender

\begin{tabular}{|c|c|c|c|}
\hline Study groups & Male $(n=59)$ & Female $(n=91)$ & p-value \\
\hline \multicolumn{4}{|l|}{ Control } \\
\hline IL-6 & $2.90(0.97-6.78)$ & $8.33(3.98-14.41)$ & 0.0091 \\
\hline CRP & $156(123.8-542.5)$ & $260.8(96.88-1442)$ & 0.4518 \\
\hline TNF-Alpha & $40.86(24.45-77.32)$ & $39.7(20.33-112.0)$ & 0.8944 \\
\hline \multicolumn{4}{|l|}{ On HAART } \\
\hline IL-6 & $10.44(3.57-25.00)^{\dagger+\dagger}$ & $15.23(7.48-24.93) \mathrm{tt \dagger}$ & 0.4196 \\
\hline CRP & $1653(282.8-2513)^{++\dagger}$ & $1398(328.8-2510)+\dagger+$ & 0.8634 \\
\hline TNF-Alpha & $180.3(150.1-345.0)^{\dagger+\dagger}$ & $302.3(151.4-428.6)^{t+\dagger}$ & 0.435 \\
\hline \multicolumn{4}{|l|}{ HAART Naïve } \\
\hline IL-6 & $17.54(12.51-23.28)^{\dagger+\dagger}$ & $17.66(12.99-24.68)^{t+\dagger}$ & 0.9569 \\
\hline CRP & $1894(426.0-3264)^{\dagger+\dagger}$ & $1450(187.9-2648)^{++\dagger}$ & 0.3473 \\
\hline TNF-Alpha & $321(270.2-427.4)^{\dagger+\dagger}$ & $318.3(108.0-500.9)^{+t \dagger}$ & 0.9054 \\
\hline
\end{tabular}

\section{Discussion}

This study observed a significant increase TNF- $\alpha$, CRP and IL-6 in HIV patients. In effect, the cycle of HIV infection, immunosuppression, opportunistic disease, high TNF levels, and further induction of HIV expression could explain at least in part the progression of disease in HIV infected individuals. This study findings show six fold increase of TNF- $\alpha$ in HIV seropositive patient compare to the control group. Generally HIV infected persons are exposed to microbial translocation due to the preferential attack of the CD4 T cell at the mucosal tissue site like the gastrointestinal tract [7]. The presence of the bacteria in the interstitial space triggers immune response leading to the release of TNF- $\alpha$ by macrophage during the inflammation process. As this condition persists in HIV infection due the replicative effect of the virus there is a continuous rise in the level of TNF- $\alpha$ in the serum. High level of TNF- $\alpha$ have been noted to aid in the expression of HIV in infected cells [1-3,17] which confirms that pathogenesis of HIV is associated with high level of TNF$\alpha$. This increased level of TNF- $\alpha$ induces the production of IL- 6 by monocytic cells [18]

This could have accounted for the significant increase in IL-6 level recorded in seropositive HIV groups than that of the control group. Other cells may also secrete IL-6 during inflammation and tissue damage together with vascular endothelial cells and fibroblasts in HIV infected patient. Persistent IL-6 production could therefore be an additional risk factor for the development of hyperlipidaemia in patient receiving HAART. Co-operation between IL- 6 and TNF- $\alpha$ results in the up regulation of HIV production and potentiates the TNF- $\alpha$ - induced transcription of NFKB [18]. The high level of IL-6 induces the hepatocytes of the liver to secrete of C- reactive protein [19].

Serum C-reactive protein concentration raise as the arterial walls inflames during atherosclerosis which is common in HIV infected patients. The C-reactive protein concentration increased by more than eight folds in the seropositive HIV groups compared to the control group in our study. CRP is capable of acting as an opsonin in the host response to infection and at the same time, limiting excessive damaging inflammatory response to the host [20] Individual with High level of CRP have an increased risk for cardiovascular disease relative to those with lower CRP concentrations[16, 21, 22]

\section{Conclusion}

The present study revealed elevated levels of pro-inflammatory cytokines (IL-6, CRP and TNF-Alpha) in seropositive HIV groups compared to seronegative group. This increase further aggravates the condition of HIV patients especially those who are HAART naïve thereby affecting morbidity and mortality. Notwithstanding the toxicities associated with the use of HAART, HIV patients are encouraged to adhere to this treatment modality. 


\section{Compliance with ethical standards}

\section{Acknowledgments}

Authors are grateful to the Staff of Serology and blood bank unit of KATH for their immeasurable support.

\section{Disclosure of conflict of interest}

Authors declare that they have no competing interests.

\section{Statement of ethical approval}

The study protocol was sent for review and approval from the Committee on Human Research, Publications and Ethics, School of Medical Sciences, Kwame Nkrumah University of Science and Technology and Komfo Anokye Teaching Hospital, in Kumasi. Permission was sought from the Head of Diagnostic Directorate to undertake the study at the serology unit of the Komfo Anokye Teaching Hospital. Subjects who accepted to be part of the study were made to sign an informed consent form.

\section{Statement of informed consent}

Informed consent was obtained from all individual participants included in the study.

\section{References}

[1] Pasquereau S, Kumar A and Herbein G. (2017). Targeting TNF and TNF receptor pathway in HIV-1 infection: from immune activation to viral reservoirs. Viruses 9, 64.

[2] Hagaa T, Efird JT, Tugizov S and Palefsky JM. (2016). Increased TNF-alpha and sTNFR2 levels are associated with high-grade anal squamous intraepithelial lesions in HIV-positive patients with low CD4 level. Papillomavirus Research, 3, 1-6.

[3] Kumar A, Abbas W and Herbein G. (2013). TNF and TNF receptor superfamily members in HIV infection: new cellular targets for therapy? Mediators of Inflammation, 1-14.

[4] Borges AH, O'Connor JL, Phillips AN, Rönsholt FF, Pett S, Vjecha MJ, French MA and Lundgren JD. (2015). Factors associated with plasma IL-6 Levels during HIV infection. The Journal of Infectious Diseases, 212, 585-95.

[5] Shive CL, Biancotto A, Funderburg NT, Pilch Cooper HA, Valdez H, Margolis L, Sieg SF, McComsey GA, Rodriguez B and Lederman MM. (2012). HIV-1 is not a major driver of increased plasma IL-6 levels in chronic HIV-1 disease. Journal of Acquired Immune Deficiency Syndromes, 61(2), 145-152.

[6] Salter ML, Lau B, Mehta SH, Go VF, Leng S and Kirk GD. (2013). Correlates of elevated interleukin-6 and C-reactive protein in persons with or at high-risk for HCV and HIV infections. Journal of Acquired Immune Deficiency Syndromes, 64(5), 1-14.

[7] Wiredu OK, Edzeamey FJ, Dompreh A, Awuah M, Ako AK, Sampong BB, Ahmed S and Yeboah EK. (2018). Lymphocyte subset (CD3, CD4 and CD8 Cells) and their ratios in HIV patients on highly active antiretroviral therapy (HAART) and HAART naïve patients. International Journal of Microbiology and Advanced Immunology, 06(2), 92-95.

[8] Ishihara K and Hirano T. (2002). IL-6 in autoimmune disease and chronic inflammatory proliferative disease. Cytokine Growth Factor Review, 13, 357-68.

[9] Rifai N, Joubran R, Yu H, Asmi M and Jouma M. (1999). Inflammatory markers in men with angiographically documented coronary heart disease. Clinical Chemistry, 45, 1967-73.

[10] Edzeamey FJ and Ako AK (2018). HIV Infection and Therapeutic Interventions: Review on HIV Infection Biology, Highly Active Antiretroviral Therapy (HAARTs), Hepatotoxicity, Nephrotoxicity and Dyslipidemia. International Journal of Research and Reports in Hematology, 1(1): 1-11

[11] Ownby RL, Kumar AM, Fernandez JB, Moleon-Borodowsky I, Gonzalez L, Eisdorfer S, Waldrop-Valverde D and Kumar M. (2009). Tumor Necrosis Factor-alpha Levels in HIV-1 Seropositive Injecting Drug Users. Journal of Neuroimmune Pharmacology, 4(3), 350-358. 
[12] Lau DC, Dhillon B, Yan H, Szmitko PE and Verma S. (2005). Adipokines: molecular links between obesity and atheroslcerosis. American Journal of Physiology-Heart and Circulatory, 288, H2031-41.

[13] Pepys MB, and Hirschfield GM. (2003). C-reactive protein: a critical update. Journal of Clinical Investigation, 111, 1805-12.

[14] Clyne B, and Olshaker JS. (1999). The C-reactive protein. Journal of Emergency Medicine, 17, 1019-25.

[15] Lau B, Sharrett AR, Kingsley LA, Post W, Palella FJ, Visscher B and Gange SJ. (2006). C-reactive protein is a marker for human immunodeficiency virus disease progression. Archives of Internal Medicine, 166, 64-70.

[16] Triant VA, Meigs JB and Grinspoon SK. (2009). Association of C - reactive protein and HIV infection with acute myocardial infarction. Journal of Acquired Immune Deficiency Syndromes, 51(3), 268-273.

[17] Eylar EH, Lefranc CE, Yamamura Y, Ineabely Báez I, Colón-Martinez SL, Rodriguez N and Breithaupt TB. (2001). HIV infection and aging: enhanced Interferon- and Tumor Necrosis Factor-alpha production by the CD8+ CD28T subset. BMC Immunology 2, 10.

[18] Poli G, Kinter AL and Fauci AS. (1994). Interleukin 1 induces expression of the human immunodeficiency virus alone and in synergy with interleukin 6 in chronically infected U1 cells: inhibition of inductive effects by the interleukin 1 receptor antagonist. Proceedings of the National Academy of Sciences of the United States of America, 91, 108-12.

[19] Gauldie J, Richards C, Northemann W, Fey G and Baumann H. (1989). IFN $32 / B S F 2 / I L-6$ is the monocyte-derived HSF that regulates receptor-specific acute phase gene regulation in hepatocytes. Annals of the New York Academy of Sciences, 557(1), 46-59.

[20] Black S, Kushner I and Samols D. (2004). C-reactive protein. Journal of Biological Chemistry, 279, 48487-90.

[21] Ridker PM. (2003). Clinical application of C-reactive protein for cardiovascular disease detection and prevention. Circulation, 107, 363-9.

[22] Lau B, Sharrett AR, Kingsley LA, Post W, Palella FJ, Visscher B and Gange SJ. (2006). C - reactive protein is a Marker for Human Immunodeficiency Virus Disease Progression. Archives of Internal Medicine, 166, 64-70.

\section{How to cite this article}

Wiredu OK, Edzeamey FJ, Frempong MT, Gborgblorvor D, Sampong BB, Awuah M and Dompreh A. (2018). Levels of proinflammatory biomarkers among HIV patients on highly active antiretroviral therapy (HAART) and HAART naive patients GSC Biological and Pharmaceutical Sciences, 4(2), 17-23. 